Check for updates

Cite this: RSC Adv., 2019, 9, 1270

Received 20th September 2018 Accepted 10th December 2018

DOI: $10.1039 / \mathrm{c} 8 \mathrm{ra07827k}$

rsc.li/rsc-advances

\section{Tunable luminescence evolution and energy transfer behavior of $\mathrm{Na}_{3} \mathrm{Sc}_{2}\left(\mathrm{PO}_{4}\right)_{3}: \mathrm{Ce}^{3+} / \mathrm{Tb}^{3+} / \mathrm{Eu}^{3+}$ phosphors $\dagger$}

\author{
Yufeng Zhang, ${ }^{a}$ Jie Xiong, ${ }^{a}$ Dingyi Shen, ${ }^{a}$ Wenpeng Xia, ${ }^{a}$ Jie Yu, ${ }^{b}$ Yanfei Zhang, ${ }^{c}$ \\ Jun Yang, (D) *a Shanshan Hu, ${ }^{a}$ Yuxin Wan, ${ }^{d}$ Haili Wen, ${ }^{d}$ Hang Ye ${ }^{d}$ and Yucan Liu ${ }^{d}$
}

A series of color-tunable emitting $\mathrm{Na}_{3} \mathrm{Sc}_{2}\left(\mathrm{PO}_{4}\right)_{3}: \mathrm{Ce}^{3+} / \mathrm{Tb}^{3+} / \mathrm{Eu}^{3+}$ (NSPO) phosphors were prepared by a combination of hydrothermal synthesis and low temperature calcination. The phase structure, photoluminescence and energy transfer properties of the samples were studied in detail. The tunable colors were obtained by co-doping the $\mathrm{Tb}^{3+}$ ions into the NSPO:Ce ${ }^{3+}$ or $\mathrm{NSPO}: \mathrm{Eu}^{3+}$ phosphors with varying concentrations. Under UV excitation, the energy transfers from $\mathrm{Tb}^{3+}$ to $\mathrm{Eu}^{3+}$ in the NSPO host occurred mainly via a dipole-dipole mechanism, and the critical distances of the ion pairs $\left(R_{\mathrm{c}}\right)$ was calculated to be $17.94 \AA$ by the quenching concentration method. And that, the emission colors of the $\mathrm{NSPO}: \mathrm{Tb}^{3+}, \mathrm{Eu}^{3+}$ phosphors could be adjusted from green through yellow to red because of the energy transfer from $\mathrm{Tb}^{3+}$ to $\mathrm{Eu}^{3+}$. Based on its good photoluminescence properties and abundant emission colors, the NSPO: $\mathrm{Ce}^{3+} / \mathrm{Tb}^{3+} / \mathrm{Eu}^{3+}$ phosphors might be promising as potential candidates for solid-state lighting and display fields.

\section{Introduction}

When replacing cations in certain hosts, rare earth elements are important activators for modern lighting and display applications, because they have rich emission colors for spectral conversion..$^{1-5}$ Recently, rare earth ion-doped inorganic materials have drawn a great deal of attention due to their many applications in optics, magnetics and catalysis..$^{6-8}$ In the lighting field, compared with traditional incandescent lighting, white light-emitting diodes (w-LEDs) are favored due to their higher conversion efficiency and more flexible photometric properties. ${ }^{9-11}$ Now, the main manufacturing technology of w-LEDs relies on the combination of a blue InGaN chip and a yellow light-emitting phosphor $\mathrm{Y}_{3} \mathrm{Al}_{5} \mathrm{O}_{12}: \mathrm{Ce}^{3+}$ (YAG). Although this method shows high efficiency, it exhibits a high correlated color and low color rendering index $\left(R_{\mathrm{a}}<80\right)$ because of the lack of a red component. ${ }^{12}$ Currently, a new type of w-LEDs assembly which is made by ultraviolet or near ultraviolet excitation single matrix multicolor fluorescent powders is widely used. ${ }^{13}$ Therefore, due to the need to increase the efficiency of white light

${ }^{a}$ School of Chemistry and Chemical Engineering, Southwest University, Chongqing 400715, China. E-mail: jyang@swu.edu.cn

${ }^{b}$ Academic Affairs Office, Southwest University, Chongqing 400715, China

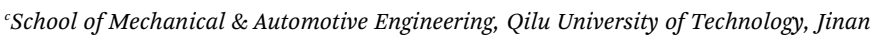
250061, China

${ }^{d}$ Chongqing Songshuqiao Middle School, Chongqing 401147, China

$\dagger$ Electronic supplementary information (ESI) available. See DOI: $10.1039 / \mathrm{c} 8 \mathrm{ra} 07827 \mathrm{k}$ emitting solid state devices, the development of the technique of combining a UV LED chip with tricolor (red, green and blue) phosphors has been proceeding. In this case, recent research has focused on finding converted luminescent phosphors with suitable emission colors, high efficiencies and high chemical stability.

Researchers have studied a variety of inorganic materials, including silicates, aluminates, phosphates, nitrides, molybdates and tungstates. Among them, the rare earth ion-doped phosphate materials have attracted much attention because of their abundance, good chemical stability and low sintering temperature. ${ }^{14-18}$ Luminescence of rare earth ions in orthophosphates with the general formula $\mathrm{M}_{3}^{\mathrm{I}} \mathrm{M}^{\mathrm{II}}\left(\mathrm{PO}_{4}\right)_{3}$ or $\mathrm{M}_{3}^{\mathrm{I}} \mathrm{M}_{2}^{\mathrm{II}}\left(\mathrm{PO}_{4}\right)_{3}\left(\mathrm{M}^{\mathrm{I}}=\mathrm{Ca}, \mathrm{Sr}, \mathrm{Ba}, \mathrm{Pb}, \mathrm{K}\right.$ and $\mathrm{Na} ; \mathrm{M}^{\mathrm{II}}=\mathrm{La}, \mathrm{Y}, \mathrm{Gd}, \mathrm{Sc}$, $\mathrm{Bi}$ and In) are widely researched. ${ }^{19-21}$ As early as the 1980s, scandium phosphate $\mathrm{Na}_{3} \mathrm{Sc}_{2}\left(\mathrm{PO}_{4}\right)_{3}$ (NSPO) was reported and developed as an ion conductor. ${ }^{22,23}$ During 2013-2016, Hirohumi studied the luminescent properties of $\mathrm{Eu}^{2+}$-doped NSPO respectively. ${ }^{24,25}$ Recently, Huang's group studied the luminescent properties of $\mathrm{Eu}^{3+}$ doped NSPO phosphors and NSPO: $\mathrm{Ce}^{3+}, \mathrm{Tb}^{3+}$ phosphors; ${ }^{26,27}$ they also reported $\mathrm{Dy}^{3+}$ and $\mathrm{Eu}^{3+}$ co-doped NSPO phosphors. ${ }^{28}$ Among these research reports, the high temperature solid-state reaction method is the most common route to produce orthophosphates. However, it has many disadvantages such as complex experimental conditions, cumbersome procedures and high reaction temperatures (such as $1300{ }^{\circ} \mathrm{C}$ )..$^{25-31}$ Therefore, from the point of view of simplicity and energy saving, there is still an urgent need to develop a simple and mild solution 
phase method to produce pure orthophosphate micro/ nanocrystals.

Luminescent lanthanide ions can be divided into two categories: $4 \mathrm{f}-4 \mathrm{f}$ and $5 \mathrm{~d}-4 \mathrm{f}$ transitions, respectively. Due to the strict ban of $4 \mathrm{f}-4 \mathrm{f}$ transitions, their emission peak widths are very narrow and fixed. For $5 \mathrm{~d}-4 \mathrm{f}$ transitions, the $5 \mathrm{~d}$ orbitals are exposed to the environment and their emission spectra are strongly influenced by the host, such as the strength of the crystal field. ${ }^{32}$ We know that the energy transfer process may be affected by the presence of carrier traps or defects in the host lattice. Therefore, it is possible for the tiny dopants with different affinities to change the trap configuration and thus significantly improve the efficiency. ${ }^{33}$ It is clear that $\mathrm{Tb}^{3+}$ acts as a good sensitizer to increase the luminescence efficiency of $\mathrm{Eu}^{3+}$ ions in $\mathrm{Na}_{3} \mathrm{Gd}\left(\mathrm{PO}_{4}\right)_{2}{ }^{34} \mathrm{CaYAlO}_{4},{ }^{35} \mathrm{SrMg}_{2} \mathrm{LaW}_{2} \mathrm{O}_{12}$ (ref. 36) and $\mathrm{Y}_{2} \mathrm{O}_{3}$ (ref. 37) phosphors. Therefore, $\mathrm{Tb}^{3+}$ and $\mathrm{Eu}^{3+}$ ions can be used as efficient luminescent centers in real devices. $\mathrm{Ce}^{3+}$ ions with permissive $5 \mathrm{~d}-4 \mathrm{f}$ emission transitions from 300 to $400 \mathrm{~nm}$ have been widely studied as efficient activators. ${ }^{38,39} \mathrm{In}$ addition, $\mathrm{Tb}^{3+}$ may also be an important activator with only weak absorption peaks at about $300-400 \mathrm{~nm}$ due to the $4 \mathrm{f}-4 \mathrm{f}$ absorption transitions..$^{40}$ Therefore, $\mathrm{Ce}^{3+}$ ions co-doped in the host can not only increase the emission intensity of $\mathrm{Tb}^{3+}$ ions but also cause excitation in the ultraviolet region of 200$400 \mathrm{~nm}$, thereby overcoming the defects of the $\mathrm{Ce}^{3+}$ or $^{\mathrm{Tb}^{3+}}$ ions doped alone. So far, many $\mathrm{Ce}^{3+}$ and $\mathrm{Tb}^{3+}$ co-doped materials have been reported including silicates, aluminates, phosphates, fluorides and oxynitrides. ${ }^{4-44}$ To the best of our knowledge, the energy transfer of $\mathrm{Tb}^{3+} \rightarrow \mathrm{Eu}^{3+}$ in NSPO materials by a simple method has little been reported in the previous literature. ${ }^{24,25,27}$

In this work, $\mathrm{Tb}^{3+}-\mathrm{Eu}^{3+}\left(\mathrm{Ce}^{3+}-\mathrm{Tb}^{3+}\right)$ co-doped NSPO phosphors were firstly synthesized by a combination of hydrothermal method and low temperature calcinations $\left(800^{\circ} \mathrm{C}\right)$. And we obtained tunable emission colors such as red $\left(\mathrm{Eu}^{3+}\right)$, green $\left(\mathrm{Tb}^{3+}\right)$, blue-violet $\left(\mathrm{Ce}^{3+}\right)$, yellow $\left(\mathrm{Tb}^{3+}-\mathrm{Eu}^{3+}\right)$ and so on. The energy transfer mechanisms, the lifetimes, luminescence properties, crystallinity and color tunability of the NSPO:Tb ${ }^{3+}$ $\mathrm{Eu}^{3+}$ phosphors were also investigated. Based on multicolor tunable luminescence, the $\mathrm{NSPO}: \mathrm{Ce}^{3+} / \mathrm{Tb}^{3+} / \mathrm{Eu}^{3+}$ phosphors may have potential applications in the field of color displays, fluorescent lamps, solid-state lighting and UV-pumped LEDs.

\section{Experimental section}

\subsection{Materials}

The rare earth oxides including $\mathrm{Sc}_{2} \mathrm{O}_{3}$ (A.R.), $\mathrm{CeO}_{2}$ (99.99\%), $\mathrm{Eu}_{2} \mathrm{O}_{3}(99.99 \%)$ and $\mathrm{Tb}_{4} \mathrm{O}_{7}(99.99 \%)$ were purchased from Chuandong Chemical Reagents Company (China). The raw materials sodium citrate $\left(\mathrm{Na}_{3} \mathrm{C}_{6} \mathrm{H}_{5} \mathrm{O}_{7} \cdot 2 \mathrm{H}_{2} \mathrm{O}\right)$ (A.R.), sodium phosphate tribasic dodecahydrate $\left(\mathrm{Na}_{3} \mathrm{PO}_{4} \cdot 12 \mathrm{H}_{2} \mathrm{O}\right)$ (A.R.) and hydrogen peroxide $\left(\mathrm{H}_{2} \mathrm{O}_{2}\right)$ were purchased from Aladdin (China). All chemicals were used directly without further purification. The $\mathrm{RECl}_{3}(\mathrm{RE}=\mathrm{Sc}, \mathrm{Ce}, \mathrm{Eu}$ and $\mathrm{Tb})$ were firstly obtained by dissolving the corresponding rare earth oxides in dilute $\mathrm{HCl}$ solution. In addition, it was necessary to add $\mathrm{H}_{2} \mathrm{O}_{2}$ when dissolving $\mathrm{CeO}_{2}$ in dilute $\mathrm{HCl}$ solution.

\subsection{Synthesis}

In a typical process of preparing $\mathrm{Na}_{3} \mathrm{Sc}_{2}\left(\mathrm{PO}_{4}\right)_{3}$ host, $2 \mathrm{mmol}$ $\mathrm{Na}_{3} \mathrm{C}_{6} \mathrm{H}_{5} \mathrm{O}_{7} \cdot 2 \mathrm{H}_{2} \mathrm{O}$ was added to $30 \mathrm{~mL}$ deionized water. After vigorous stirring for $30 \mathrm{~min}, 2 \mathrm{mmol} \mathrm{ScCl}_{3}$ was added into the above solution for $30 \mathrm{~min}$. Then, it was kept stirring for another 30 min. Subsequently, $2 \mathrm{mmol} \mathrm{Na} \mathrm{PO}_{4} \cdot 12 \mathrm{H}_{2} \mathrm{O}$ was added into the above reaction solution. After additional agitation for $15 \mathrm{~min}$, the obtained mixing solution was transferred into a $50 \mathrm{ml}$ Teflon-lined stainless steel autoclave and maintained at $180{ }^{\circ} \mathrm{C}$ for $24 \mathrm{~h}$. When autoclave cooled to room temperature naturally, the obtained samples were collected by centrifugation, washed several times with deionized water and ethanol and then dried at $60{ }^{\circ} \mathrm{C}$ for $24 \mathrm{~h}$. Finally, the obtained precipitates were transferred to muffle stove with the temperature at $800{ }^{\circ} \mathrm{C}$ for $2 \mathrm{~h}$ to get the final products $\mathrm{Na}_{3} \mathrm{Sc}_{2}\left(\mathrm{PO}_{4}\right)_{3}$ (marked as NSPO). A series of NSPO: $\mathrm{Ce}^{3+} / \mathrm{Tb}^{3+} / \mathrm{Eu}^{3+}$ and NSPO: $\mathrm{Tb}^{3+}, \mathrm{Eu}^{3+} /$ $\mathrm{Ce}^{3+}, \mathrm{Tb}^{3+}$ phosphors have been synthesized using the same method above except for different stoichiometric amounts of $\mathrm{RECl}_{3}(\mathrm{RE}=\mathrm{Sc}, \mathrm{Ce}, \mathrm{Eu}$ and $\mathrm{Tb})$. Our sample synthesis has good reproducibility, which can also be seen from the XRD, SEM and PL results of the samples in the Results and discussion section.

\subsection{Characterization}

X-ray power diffraction (XRD) measurements were performed on a Purkinje General Instrument MSALXD3 using $\mathrm{Cu} \mathrm{K} \alpha$ radiation $(\lambda=0.15406 \mathrm{~nm})$. The morphology analysis was carried out on a field emission scanning electron microscopy (FESEM, Hitachi, S-4800). The PL excitation and emission spectra were detected by an F-7000 spectrophotometer (Hitachi, Japan) equipped with a $150 \mathrm{~W}$ xenon lamp as excitation source. The decay lifetimes were measured by FLS980 (Edinburgh Instrument).

\section{Results and discussion}

\subsection{Phase, structure and morphology}

The crystal structure and phase composition of the samples were studied by X-ray diffraction (XRD). Fig. 1A shows the XRD patterns of pure NSPO (a), NSPO:0.1 $\mathrm{Ce}^{3+}(\mathrm{b}), \mathrm{NSPO}: 0.1 \mathrm{~Tb}^{3+}(\mathrm{c})$, NSPO:0.1 $\mathrm{Eu}^{3+}(\mathrm{d}), \mathrm{NSPO}: 0.1 \mathrm{~Tb}^{3+}, 0.1 \mathrm{Eu}^{3+}(\mathrm{e})$ and NSPO:0.1 $\mathrm{Ce}^{3+}$, $0.01 \mathrm{~Tb}^{3}$ (f), respectively. All diffraction peaks can be attributed to the pure monoclinic NSPO phase, which is consistent with the standard card (JCPDS\#44-0567). No other impurities are detected, indicating that the resulting products consist of a microscopic substructure with high crystallinity. The results show that the doped $\mathrm{Ln}^{3+}$ ions do not change the phase of the matrix significantly, and the dopant ions have been successfully dissolved in the lattice of NSPO host. It is well known that the chemical properties and ionic radius of the rare earth ions are similar, so we confirm that the $\mathrm{Ce}^{3+}, \mathrm{Tb}^{3+}, \mathrm{Eu}^{3+}, \mathrm{Ce}^{3+} / \mathrm{Tb}^{3+}$ or $\mathrm{Tb}^{3+} / \mathrm{Eu}^{3+}$ are well incorporated into the NSPO host lattice. It is worth noting that the characteristic diffraction peak (112) is shifted to a lower diffraction angle. This means that the incorporated ions cause the lattice to expand and the doped rare earth ions have replaced the ions in the body. This further shows that $\mathrm{Ce}^{3+}, \mathrm{Tb}^{3+}$ and $\mathrm{Eu}^{3+}$ are successfully constructed into 


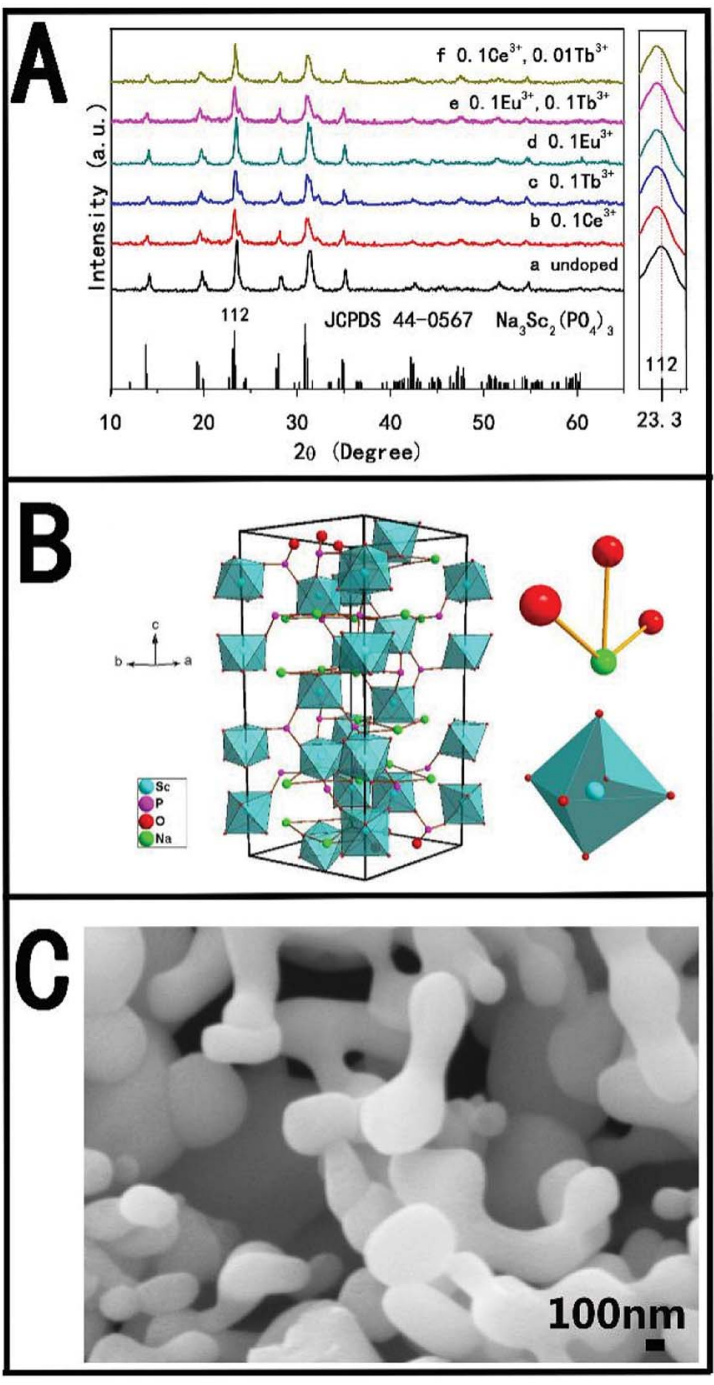

Fig. 1 (A) XRD patterns of pure NSPO (a) and NSPO: $\operatorname{Ln}^{3+}(b-f)$; (B) the structure of the NSPO crystals and the sites of $\mathrm{Na}^{+}$and $\mathrm{Sc}^{3+}$ polyhedrons, respectively; (C) SEM of the prepared NSPO samples.

NSPO host material by doping strategy. Fig. 1B presents the cell structure of the NSPO crystal and the coordination environment of cation $\mathrm{Sc}^{3+} / \mathrm{Na}^{+}$with $\mathrm{O}$ atoms. The detailed structural parameters and crystallographic data for NSPO crystal are listed in Table S1 (ESI $\dagger$ ). In the monoclinic NSPO structure, each $\mathrm{Sc}^{3+}$ ion is coordinated by its nearest six oxygen atoms to form a regular quadrangular pyramid where $\mathrm{Sc}^{3+}$ ion is located in the symcenter. The $\mathrm{Na}^{+}$ion is coordinated by eight oxygen atoms. The NSPO compound with lattice constants $a=b=8.931$ and $c$ $=22.3267$ crystallizes in the $R \overline{3} c$ space group. The relevant atomic parameter data are listed in Table S2 (ESI†े). As shown in Fig. 1C, we found that the NSPO products are relatively uniform nanoparticles with smaller size of $300 \mathrm{~nm}$ comparing with the literature reports ${ }^{26-28}$ (Fig. S1, ESI $\dagger$ ).

\subsection{Photoluminescence properties}

A series of independently doped NSPO: $\mathrm{Ln}^{3+}(\mathrm{Ln}=\mathrm{Ce} / \mathrm{Tb} / \mathrm{Eu})$ and double doped NSPO: $\mathrm{Ln}^{3+}(\mathrm{Ln}=\mathrm{Tb}, \mathrm{Eu} / \mathrm{Ce}, \mathrm{Tb})$ phosphors were synthesized and their respective luminescence spectra were studied. $\mathrm{Eu}^{3+}$ ions are noted activators in various host lattices. Fig. 2a displays the PLE and PL spectra of NSPO:0.1Eu ${ }^{3+}$ phosphors. Monitored at $619 \mathrm{~nm}$, the excitation spectrum includes a weak broad band at $275 \mathrm{~nm}$, which can be attributed to the charge-transfer (CT) band from $\mathrm{O}^{2-}$ to $\mathrm{Eu}^{3+}$ ions. There are some sharp peaks in the ultraviolet range of $300-400 \mathrm{~nm}$, which can be assigned to the $\mathrm{f} \rightarrow \mathrm{f}$ characteristic transition of $\mathrm{Eu}^{3+}\left({ }^{7} \mathrm{~F}_{0} \rightarrow{ }^{5} \mathrm{H}_{5}\right.$ at $323 \mathrm{~nm},{ }^{7} \mathrm{D}_{0} \rightarrow{ }^{5} \mathrm{D}_{4}$ at $358 \mathrm{~nm},{ }^{5} \mathrm{D}_{0} \rightarrow{ }^{5} \mathrm{~L}_{7}$ at $380 \mathrm{~nm}$ and ${ }^{7} \mathrm{~F}_{0} \rightarrow{ }^{5} \mathrm{~L}_{6}$ at $\left.394 \mathrm{~nm}\right) .{ }^{45}$ The strongest one is located at near-UV region of $394 \mathrm{~nm}$ which indicates that the phosphor is suitable for excitation of UV LED chips. Upon excitation at $394 \mathrm{~nm}$, the PL spectrum includes two emissions peaks at 594 and $619 \mathrm{~nm}$ originating from the ${ }^{5} \mathrm{D}_{0} \rightarrow{ }^{7} \mathrm{~F}_{1}$ and ${ }^{5} \mathrm{D}_{0} \rightarrow{ }^{7} \mathrm{~F}_{2}$ transitions of $\mathrm{Eu}^{3+}$ activator, respectively. We know that the relative intensity of emission is affected obviously by the replaced position of activator $\mathrm{Eu}^{3+}$ in host lattice. The ${ }^{5} \mathrm{D}_{0} \rightarrow{ }^{7} \mathrm{~F}_{1}$ transition corresponding to the magnetic dipole moment is less sensitive to the crystallographic site symmetry of activator $\mathrm{Eu}^{3+}$ than the ${ }^{5} \mathrm{D}_{0} \rightarrow{ }^{7} \mathrm{~F}_{2}$ transition corresponding to the electrical dipole moment transition. Therefore, if $\mathrm{Eu}^{3+}$ occupies a high symmetry site, the ${ }^{5} \mathrm{D}_{0} \rightarrow{ }^{7} \mathrm{~F}_{1}$ emission will be stronger; whereas the ${ }^{5} \mathrm{D}_{0} \rightarrow{ }^{7} \mathrm{~F}_{2}$ emission dominates the emission spectrum if $\mathrm{Eu}^{3+}$ ions locate in a low symmetry site (Fig. 2a). ${ }^{46,47}$

We compared the PL and PLE of the $\mathrm{Na}_{3} \mathrm{Sc}_{2}\left(\mathrm{PO}_{4}\right)_{3}$ doped with $\mathrm{Eu}^{3+}$ by both methods (ceramic and hydrothermal) in Fig. S2 (ESI $\dagger$ ). Under excitation of $394 \mathrm{~nm}$, the PL spectra of $\mathrm{Na}_{3} \mathrm{Sc}_{2}\left(\mathrm{PO}_{4}\right)_{3}: \mathrm{Eu}^{3+}$ phosphors by both methods both exhibited four characteristic emission bands with 594(593), 619(621), 654 and $699 \mathrm{~nm}$ corresponding to ${ }^{5} \mathrm{D}_{0} \rightarrow{ }^{7} \mathrm{~F}_{1},{ }^{5} \mathrm{D}_{0} \rightarrow{ }^{7} \mathrm{~F}_{2},{ }^{5} \mathrm{D}_{0}$ $\rightarrow{ }^{7} \mathrm{~F}_{3}$ and ${ }^{5} \mathrm{D}_{0} \rightarrow{ }^{7} \mathrm{~F}_{4}$ transitions, respectively. The emission spectrum of the sample by ceramic method appears to be more refined and has higher luminous intensity at 654 and $699 \mathrm{~nm}$, which can be attributed to higher crystallinity caused by the ceramic method at higher temperature. In the PLE spectra of

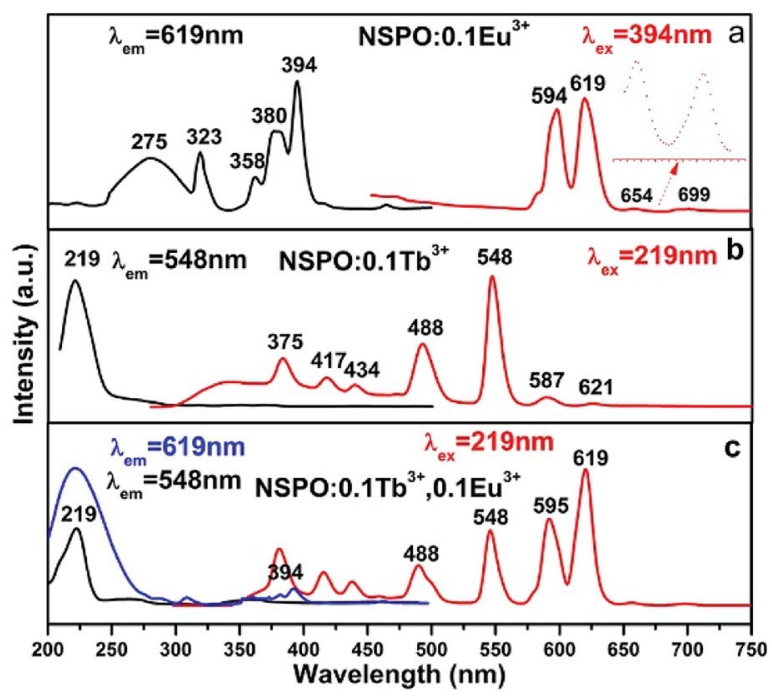

Fig. $2 \mathrm{PL}$ and PLE spectra of the NSPO:0.1Eu ${ }^{3+}$ phosphor (a), NSPO:0.1 $\mathrm{Tb}^{3+}$ phosphor (b) and NSPO:0.1 $\mathrm{Tb}^{3+}, 0.1 \mathrm{Eu}^{3+}$ phosphor (c), respectively. 
$\mathrm{Na}_{3} \mathrm{Sc}_{2}\left(\mathrm{PO}_{4}\right)_{3}: \mathrm{Eu}^{3+}$ phosphors by both methods, the broad band in the 250-300 $\mathrm{nm}$ region was both attributed to the CTB transition from the fully filled $2 \mathrm{p}$ orbitals of $\mathrm{O}^{2-}$ ions to the partially filled $4 \mathrm{f}$ orbitals of $\mathrm{Eu}^{3+}$. Furthermore, these narrow PLE peaks located at around 323(318), 358(364), 380(384) and $394 \mathrm{~nm}$ were all attributed to the intra-4f transitions of $\mathrm{Eu}^{3+}$ ions from ${ }^{7} \mathrm{~F}_{0}$ level to ${ }^{5} \mathrm{H}_{6},{ }^{5} \mathrm{D}_{4},{ }^{5} \mathrm{~L}_{7}$ and ${ }^{5} \mathrm{~L}_{6}$ level, respectively. Compared with Fig. S2A(a), $\dagger$ there was no peak at $297 \mathrm{~nm}$ in Fig. S2B(a) $†$ because of the overlap of the CTB band and the ${ }^{7} \mathrm{~F}_{0}$ $\rightarrow{ }^{5} \mathrm{~F}_{J}$ transition of $\mathrm{Eu}^{3+}$. The excitation spectrum of the sample by ceramic method appears to be more refined, which can be also attributed to higher crystallinity caused by the ceramic method at higher temperature.

Fig. $2 \mathrm{~b}$ shows the PLE and PL spectra of NSPO:0.1 $\mathrm{Tb}^{3+}$. We know that $\mathrm{Tb}^{3+}$ has a simple $4 \mathrm{f}$ configuration energy level structure with low energy state ${ }^{7} \mathrm{~F}_{J}(J=6,5, \ldots, 0)$ and excited states ${ }^{5} \mathrm{D}_{3,4}$. The excitation spectrum (left) at room temperature (RT) is recorded by monitoring with bright green emission at $548 \mathrm{~nm}$, which showed a strong spectral band at $219 \mathrm{~nm}$ owing to the $4 \mathrm{f}^{8} \rightarrow 4 \mathrm{f}^{7} 5 \mathrm{~d}^{1}$ transition of the $\mathrm{Tb}^{3+}$ ions. Here, we can see several weak peaks in the range of $300-500 \mathrm{~nm}$, which are caused by the spin and orbital forbidden intra-4f transitions (enlarged and shown in Fig. S3 $\dagger$ ). Excited at the wavelength of $219 \mathrm{~nm}$, the NSPO:0.1 $\mathrm{Tb}^{3+}$ samples have two emission groups, one is the blue emission caused by the ${ }^{5} \mathrm{D}_{3} \rightarrow{ }^{7} \mathrm{~F}_{J}$ transitions, and the other is the green emission caused by the ${ }^{5} \mathrm{D}_{4} \rightarrow{ }^{7} \mathrm{~F}_{J}$ transitions. Four typical transitions from ${ }^{5} \mathrm{D}_{4}$ level down to ${ }^{7} \mathrm{~F}_{J}$ levels of $4 \mathrm{f}^{8}$ configuration of $\mathrm{Tb}^{3+}$ were observed, that is, ${ }^{5} \mathrm{D}_{4} \rightarrow$ ${ }^{7} \mathrm{~F}_{6}$ at $488 \mathrm{~nm},{ }^{5} \mathrm{D}_{4} \rightarrow{ }^{7} \mathrm{~F}_{4}$ at $587 \mathrm{~nm},{ }^{5} \mathrm{D}_{4} \rightarrow{ }^{7} \mathrm{~F}_{3}$ at $621 \mathrm{~nm}$ and ${ }^{5} \mathrm{D}_{4} \rightarrow{ }^{7} \mathrm{~F}_{5}$ at $548 \mathrm{~nm}$ (the strongest one). Furthermore, there are three weaker emission peaks at $375 \mathrm{~nm}, 417 \mathrm{~nm}$ and $434 \mathrm{~nm}$, which can be attributed to the ${ }^{5} \mathrm{D}_{3} \rightarrow{ }^{7} \mathrm{~F}_{6},{ }^{5} \mathrm{D}_{3} \rightarrow{ }^{7} \mathrm{~F}_{5}$ and ${ }^{5} \mathrm{D}_{3} \rightarrow$ ${ }^{7} \mathrm{~F}_{4}$ transitions of $\mathrm{Tb}^{3+}$, respectively. The emission spectra illustrate that phosphor NSPO:0.1 $\mathrm{Tb}^{3+}$ shows an intense green emission. Comparing the excitation band of NSPO:0.1 $\mathrm{Eu}^{3+}$ with the emission band of NSPO:0.1 $\mathrm{Tb}^{3+}$ (Fig. 2a and b), a meaningful spectral overlap was observed, which facilitated the transfer energy from $\mathrm{Tb}^{3+}$ to $\mathrm{Eu}^{3+}$.

Fig. 2c shows the PLE and PL spectra of the typical NSPO:0.1 $\mathrm{Tb}^{3+}, 0.1 \mathrm{Eu}^{3+}$ sample. The excitation spectra under the detection wavelength of $619 \mathrm{~nm}$ and $548 \mathrm{~nm}$ (Fig. 2c) are both the same as the excitation spectra of the single doped $\mathrm{Tb}^{3+}$ in Fig. $2 b(219 \mathrm{~nm})$, indicating that double doped NSPO phosphors can be used as a green and red two-color phosphors in near-UV pumped white LEDs. On the other hand, the emission peaks of the $\mathrm{Tb}^{3+}-\mathrm{Eu}^{3+}$ co-doped phosphors under $219 \mathrm{~nm}$ excitation were observed at $619 \mathrm{~nm}\left({ }^{5} \mathrm{D}_{0}{ }^{-}{ }^{7} \mathrm{~F}_{2}\right)$ and $548 \mathrm{~nm}\left({ }^{5} \mathrm{D}_{4}{ }^{-}{ }^{7} \mathrm{~F}_{5}\right)$, which are attributed to the $\mathrm{Eu}^{3+}$ and $\mathrm{Tb}^{3+}$ ions, respectively. Moreover, $595 \mathrm{~nm}\left({ }^{5} \mathrm{D}_{0}{ }^{-}{ }^{7} \mathrm{~F}_{1}\right)$ in the orange region of $\mathrm{Eu}^{3+}$ as well as $488 \mathrm{~nm}$ $\left({ }^{5} \mathrm{D}_{4}{ }^{-7} \mathrm{~F}_{6}\right)$ in the blue region of $\mathrm{Tb}^{3+}$ can be also observed in the NSPO:0.1 $\mathrm{Tb}^{3+}, 0.1 \mathrm{Eu}^{3+}$ phosphors. From the Fig. 2, we can see that the co-doping of the $\mathrm{Tb}^{3+}$ ions have greatly improved the $\mathrm{Eu}^{3+}$ emission under same irradiation by comparing the emission spectra of the NSPO:0.10 $\mathrm{Tb}^{3+}, 0.1 \mathrm{Eu}^{3+}$ (Fig. 2c) and NSPO:0.1 $\mathrm{Eu}^{3+}$ phosphors (Fig. 2a). Most notably, the intensity of the characteristic emitter region of $\mathrm{Tb}^{3+}$ is weaker than that of $\mathrm{Eu}^{3+}$, which provides sufficient evidence for effective energy

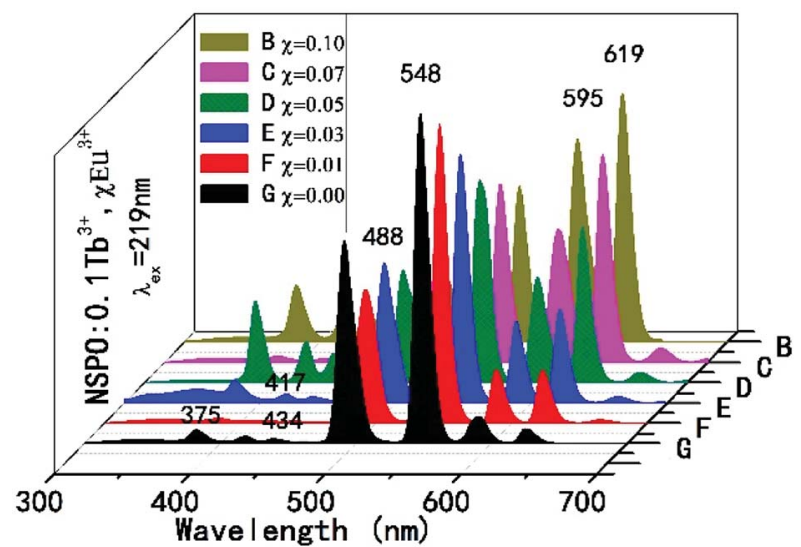

Fig. 3 Emission spectra of the NSPO:0.1 $\mathrm{Tb}^{3+}{ }_{, x E u^{3+}}$ phosphors.

transfer from the donor $\mathrm{Tb}^{3+}$ to the receptor $\mathrm{Eu}^{3+}$. Therefore, adjusting the concentrations of the two activators can change the relative intensities of the two emissions by the principle of energy transfer, which is a viable way to get multicolor light emission.

In order to further understand the energy transfer between the $\mathrm{Tb}^{3+}$ and $\mathrm{Eu}^{3+}$ ions, a series of composition-controlled samples were prepared. Fig. 3 displays the emission spectra of NSPO: $0.1 \mathrm{~Tb}^{3+}, x \mathrm{Eu}^{3+}$ phosphors with $x$ varying from 0 to 0.1 . Under excitation at $219 \mathrm{~nm}$ UV light, the phosphors show the characteristic emissions of $\mathrm{Tb}^{3+}$ as well as sharp emission peaks of $\mathrm{Eu}^{3+}$. Keeping the concentration of $\mathrm{Tb}^{3+}$ at 0.1 , the emission intensity of $\mathrm{Eu}^{3+}$ at 595/619 $\mathrm{nm}$ gradually increases with the increase of $\mathrm{Eu}^{3+}$ concentration, while the emission intensity of $\mathrm{Tb}^{3+}$ at 488/548 $\mathrm{nm}$ decreases. Under excitation of characteristic excitation peaks of $\mathrm{Tb}^{3+}$ at $219 \mathrm{~nm}$, the changing of $\mathrm{Tb}^{3+}$ and $\mathrm{Eu}^{3+}$ emission relative intensity in NSPO:0.1 $\mathrm{Tb}^{3+}, x \mathrm{Eu}^{3+}$ phosphors can further prove the efficient energy transfer from $\mathrm{Tb}^{3+}$ to $\mathrm{Eu}^{3+}$ ions. In addition, the variations of the $\mathrm{Eu}^{3+}$ and $\mathrm{Tb}^{3+}$ emission intensity in NSPO:0.1 $\mathrm{Eu}^{3+}, y \mathrm{~Tb}^{3+}$ phosphors is displayed in Fig. $\mathrm{S} 4, \dagger$ which also reflect the same result of energy transfer from $\mathrm{Tb}^{3+}$ to $\mathrm{Eu}^{3+}$.

For more directly observing the changes of relative emission intensity, Fig. 4 presents the variations of $\mathrm{Tb}^{3+}$ at $548 \mathrm{~nm}$ and $\mathrm{Eu}^{3+}$ at $619 \mathrm{~nm}$ upon changing the $\mathrm{Eu}^{3+}$ content. It is found that the emission intensity of $\mathrm{Tb}^{3+}$ ions decreases monotonically with increasing the content of the $\mathrm{Eu}^{3+}$ ions; whereas the emission intensity of $\mathrm{Eu}^{3+}$ ions as well as the energy transfer efficiency gradually increases. These results further support the generation of effective energy transfer from $\mathrm{Tb}^{3+}$ to $\mathrm{Eu}^{3+}$ ions. Here, the energy transfer efficiency $\left(\eta_{\mathrm{T}}\right)$ of $\mathrm{Tb}^{3+} \rightarrow \mathrm{Eu}^{3+}$ in the NSPO host can be estimated using the following formula: ${ }^{48}$

$$
\eta_{\mathrm{T}}=1-I_{\mathrm{S}} / I_{\mathrm{S} 0}
$$

where $I_{\mathrm{S}}$ and $I_{\mathrm{S} 0}$ are the luminescence intensities of $\mathrm{Tb}^{3+}$ in the presence and absence of $\mathrm{Eu}^{3+}$, respectively. It is clearly discovered that the value of $\eta_{\mathrm{T}}$ gradually increases with the increase of $\mathrm{Eu}^{3+}$, as shown in Fig. 4 (red line). When $x=0.1$, the $\eta_{\mathrm{T}}$ is as high as $84.72 \%$ for NSPO: $0.1 \mathrm{~Tb}^{3+}, 0.1 \mathrm{Eu}^{3+}$ phosphors. Generally speaking, energy transfer from sensitizer $\left(\mathrm{Tb}^{3+}\right)$ to activator 


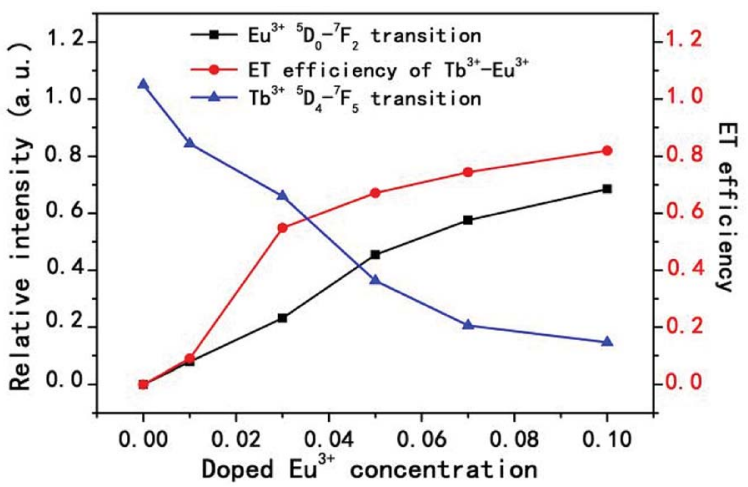

Fig. 4 Relative emission intensities of $\mathrm{Eu}^{3+}$ at $619 \mathrm{~nm}$ and $\mathrm{Tb}^{3+}$ at $548 \mathrm{~nm}$, and the ET efficiency of $\mathrm{Tb}^{3+} \rightarrow \mathrm{Eu}^{3+}$ in NSPO:0.1Tb ${ }^{3+}, x \mathrm{Eu}^{3+}$ phosphors $(x=0-0.1)$.

$\left(\mathrm{Eu}^{3+}\right)$ can be achieved through the exchange interaction or electric multipolar interaction. ${ }^{49}$ If the energy transfer is caused by the exchange interaction, the critical distance between the sensitizer and the activator should be less than 3-4 $\AA$. In contrast, electrical multipolar interaction may dominate. ${ }^{50}$ The critical distance $R_{\mathrm{c}}$ of energy transfer was calculated by using the concentration quenching method, where the critical distance $R_{\mathrm{c}}$ can be calculated by the following formula presented by Blasse: ${ }^{51}$

$$
R_{\mathrm{c}} \approx 2\left[\frac{3 V}{4 \pi x_{\mathrm{c}} N}\right]^{1 / 3}
$$

Here $V$ is the unit cell volume, $x_{\mathrm{c}}$ is the critical concentration and $N$ refers to the number of formula units per unit cell. For the NSPO host, $V=1542.20 \AA^{3}, x_{\mathrm{c}}=0.085$ and $N=6$. Based on the above formula, the critical distance for energy transfer is estimated to be about $17.94 \AA$. The value is longer than $3-4 \AA$, indicating that the energy transfer mechanism is controlled by electrical multipolar interaction in this system. We have further discussed the energy transfer mechanism for electrical multipolar interaction, which can be determined using the following relationship: $:^{52,53}$

$$
\eta_{0} / \eta \propto C^{n / 3}
$$

Here $\eta_{0}$ and $\eta$ are the luminescence quantum efficiencies of $\mathrm{Tb}^{3+}$ in the absence and presence of $\mathrm{Eu}^{3+}$, respectively; and the values of $\eta_{0} / \eta$ can be approximately calculated by the ratio of related luminescence intensities $\left(I_{\mathrm{SO}} / I_{\mathrm{S}}\right)$; $C$ is the concentration of the sum of $\mathrm{Tb}^{3+}$ and $\mathrm{Eu}^{3+}$; and $n=6,8$ and 10 correspond to dipole-dipole, dipole-quadrupole and quadrupole-quadrupole interaction, respectively. The relationships between $I_{\mathrm{So}} / I_{\mathrm{S}}$ and $C_{\left(\mathrm{Tb}^{3+}+\mathrm{Eu}^{3+}\right)^{n / 3}}$ are illustrated in Fig. 5 for NSPO:0.1 $\mathrm{Tb}^{3+}, x \mathrm{Eu}^{3+}$ phosphors. The best linear behavior was observed when $n=6$ based on the values of the fitting parameters $R^{2}$, implying that the $\mathrm{Tb}^{3+} \rightarrow \mathrm{Eu}^{3+}$ energy transfer occurs by the dipole-dipole interaction.

To further validate the energy transfer phenomenon, the decay curves of $\mathrm{Tb}^{3+}$ emission of NSPO:0.1 $\mathrm{Tb}^{3+}, x \mathrm{Eu}^{3+}(x=0$, $0.01,0.05,0.10)$ phosphors are shown in Fig. 6 . We can see that

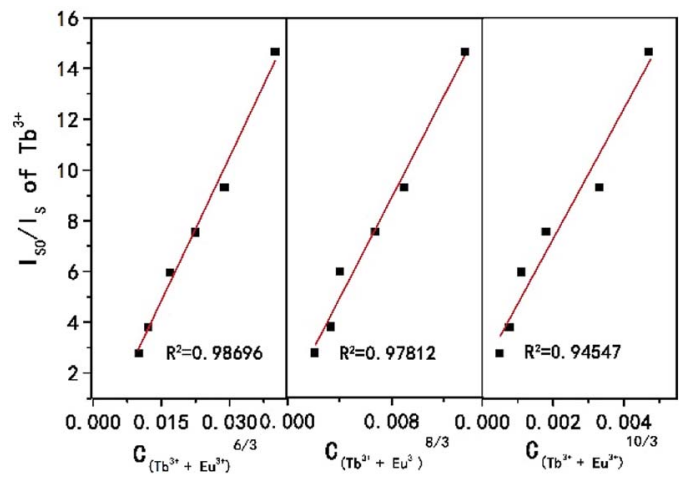

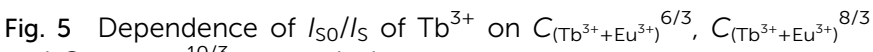

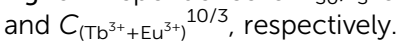

all decay curves can be well fitted by the first order exponential decay method using the formula: ${ }^{54,55}$

$$
I_{(t)}=I_{0} \exp (-t / \tau)
$$

where $\tau$ is the $1 / e$ lifetime of $\mathrm{Tb}^{3+}$. According to the formula, the decay times were calculated to be 3.36, 2.84, 1.97 and $0.86 \mathrm{~ms}$ for NSPO: $0.1 \mathrm{~Tb}^{3+}, x \mathrm{Eu}^{3+}$ with $x=0,0.01,0.05$ and 0.10 , respectively. It is easy to find that the decay lifetime of the $\mathrm{Tb}^{3+}$ ions decreases monotonically with the $\mathrm{Eu}^{3+}$ concentration increasing, which further confirms the existence of energy transfer from $\mathrm{Tb}^{3+}$ to $\mathrm{Eu}^{3+}$ ions. ${ }^{51}$ Based on the principle of energy transfer, a coordinated emission of colors can be achieved by varying the proportion of doping content. A representative CIE chromaticity diagram and coordinates of NSPO:0.1 $\mathrm{Tb}^{3+}, x \mathrm{Eu}^{3+}(x=0-0.1)$ phosphors are calculated from the relevant PL spectra (Fig. 3), as shown in Fig. 7. With the increase of $\mathrm{Eu}^{3+}$ concentration, the CIE coordinates range from $(0.2865,0.4982)$ through $(0.3657,0.4516)$ to $(0.5693,0.2976)$; and the emission colors change from green through yellow to red, accordingly. Thus, we make sure that tunable luminescence can be achieved in the new NSPO:0.10 $\mathrm{Tb}^{3+}, x \mathrm{Eu}^{3+}$ phosphors based on energy transfer.

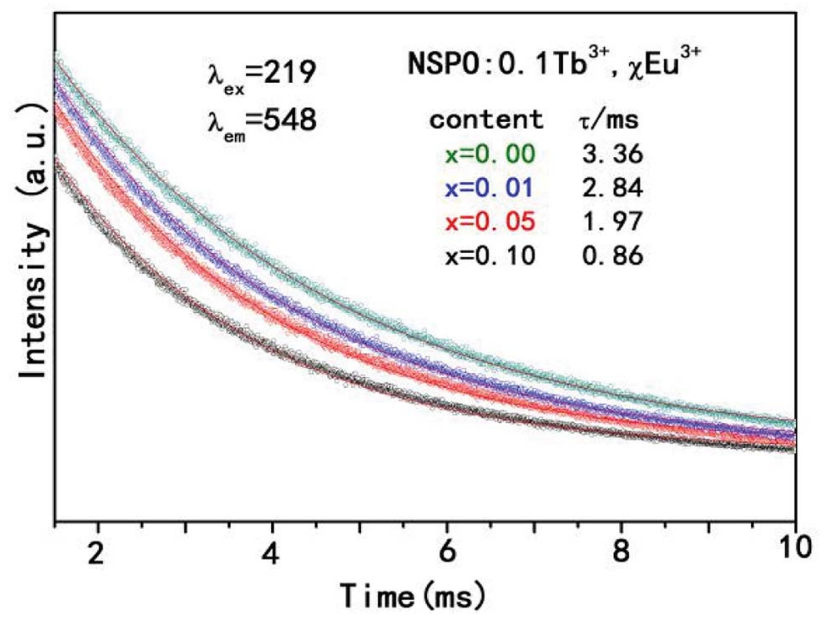

Fig. 6 Decay curves of $\mathrm{Tb}^{3+}$ in NSPO:0.1Tb ${ }^{3+}, x \mathrm{Eu}^{3+}(x=0,0.01,0.05$, 0.10) phosphors. 


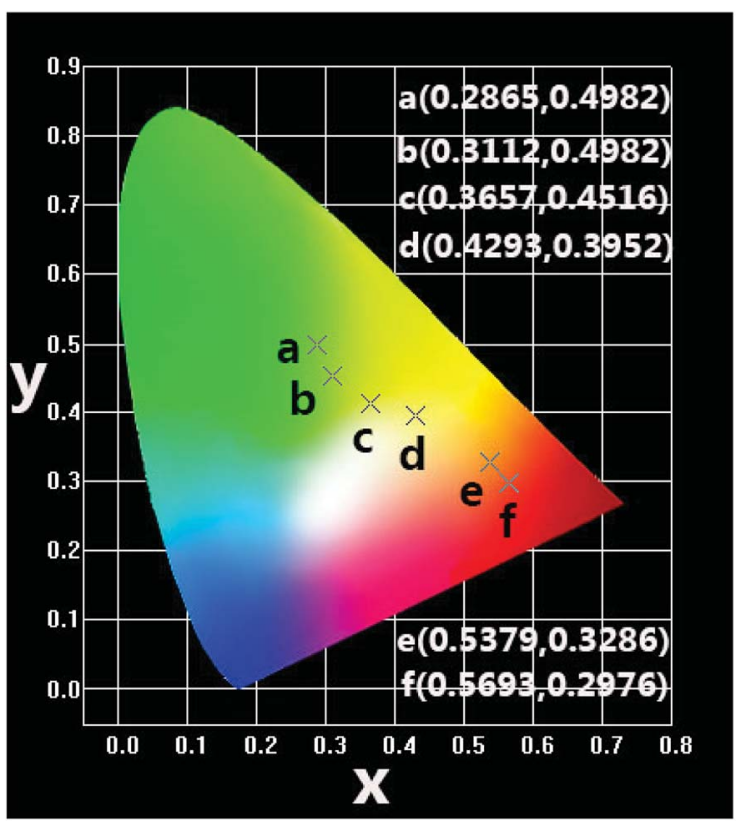

Fig. $7 \mathrm{CIE}$ chromaticity coordinates of NSPO:0.1Tb ${ }^{3+}, x \mathrm{Eu}^{3+}(x=0-$ 0.1) phosphors under $219 \mathrm{~nm}$ excitation.

Fig. 8 displays the PLE and PL spectra of $\mathrm{Ce}^{3+}$ or $\mathrm{Tb}^{3+}$ solely doped and $\mathrm{Ce}^{3+} / \mathrm{Tb}^{3+}$ co-activated NSPO phosphors. $\mathrm{Ce}^{3+}$ ions have been doped into the host as activator, and the luminescent properties have been explored. As shown in Fig. 8a, the excitation spectrum monitored at $367 \mathrm{~nm}$ for NSPO:0.1 $\mathrm{Ce}^{3+}$ phosphors exhibit a broad band centered at $278 \mathrm{~nm}$, which corresponds to the transition from the $4 \mathrm{f}$ state of $\mathrm{Ce}^{3+}$ ions to the excited $\mathrm{Ce}^{3+}$ ions $5 \mathrm{~d}$ state. Under the irradiation at $278 \mathrm{~nm}$, the phosphors can emit intense blue-violet light with a peak wavelength at $367 \mathrm{~nm}$ which can be attributed to the lowest $\mathrm{Ce}^{3+}$ $5 \mathrm{~d}$ excited state to the ground state ${ }^{2} \mathrm{~F}_{5 / 2}$ in the $\mathrm{Ce}^{3+} 4 \mathrm{f}$ configuration. Generally, with a low doping concentration of $\mathrm{Tb}^{3+}$ in the host matrix, the character emission of $\mathrm{Tb}^{3+}$ is rather weak. Fig. 8b displays the excitation and emission spectra of NSPO:0.01 $\mathrm{Tb}^{3+}$. The excitation spectrum shows a strong broad absorption band $(219 \mathrm{~nm})$ with shoulders at $257 / 273 \mathrm{~nm}$ arising

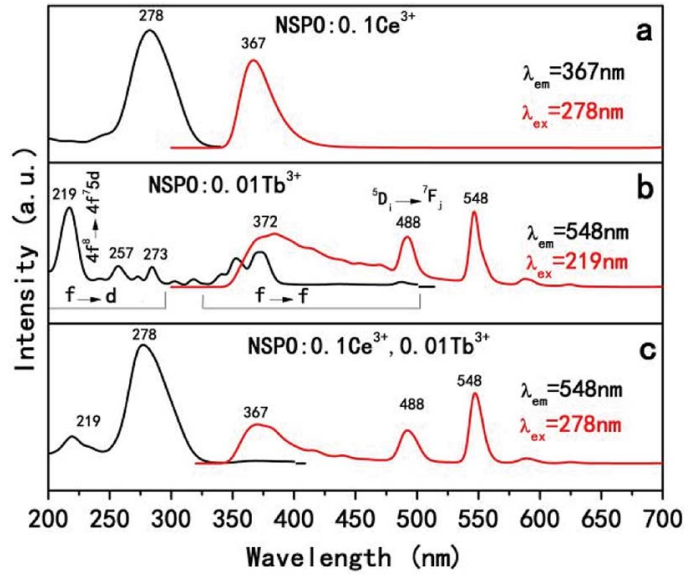

Fig. 8 PLE and PL spectra of NSPO:0.1Ce ${ }^{3+}(a), N S P O: 0.01 \mathrm{~Tb}^{3+}(b)$ and NSPO:0.1Ce $\mathrm{C}^{3+}, 0.01 \mathrm{~Tb}^{3+}$ (c), respectively. from an allowed $4 \mathrm{f}^{8}-4 \mathrm{f}^{7} 5 \mathrm{~d}$ transition and some weak narrow absorption peaks from 300 to $500 \mathrm{~nm}$ due to intra-(4f) transitions of $\mathrm{Tb}^{3+}$. The shoulders may originate from the forbidden component of the $4 \mathrm{f}^{8}-4 \mathrm{f}^{7} 5 \mathrm{~d}$ transition. ${ }^{56}$ Based on the above PL spectrum of the $\mathrm{Ce}^{3+}$ single-doped sample and the PLE spectrum of the $\mathrm{Tb}^{3+}$ single-doped sample (Fig. $8 \mathrm{a}$ and b), the spectral overlap between the broad emission band of $\mathrm{Ce}^{3+}$ and the $\mathrm{Tb}^{3+}$ excitation within the spectral range of $300-400 \mathrm{~nm}$. Thus, it is expected that a resonance-type ET from $\mathrm{Ce}^{3+}$ to $^{\mathrm{Tb}^{3+}}$ may occur in the NSPO host. As shown in Fig. 8c, the PLE and PL spectra of NSPO:0.1 $\mathrm{Ce}^{3+}, 0.01 \mathrm{~Tb}^{3+}$ phosphors were studied. When monitored at $548 \mathrm{~nm}$ of $\mathrm{Tb}^{3+}$, the excitation spectrum consists of an excitation band $(219 \mathrm{~nm})$ of $\mathrm{Tb}^{3+}$ ions assigned to $\mathrm{f}$-d transitions and a strongest excitation band $(278 \mathrm{~nm})$ of $\mathrm{Ce}^{3+}$ ions, indicating the possible energy transfer from $\mathrm{Ce}^{3+}$ to $\mathrm{Tb}^{3+}$ ions. Moreover, when excited at $278 \mathrm{~nm}$, the PL spectra show not only the broad emission peak in the blue-violet region from the electric-dipole-allowed $4 \mathrm{f}-5 \mathrm{~d}$ transitions of $\mathrm{Ce}^{3+}(367 \mathrm{~nm})$, but also the strong emission of $\mathrm{Tb}^{3+}$ at $488 \mathrm{~nm}$ and $548 \mathrm{~nm}$ $\left({ }^{5} \mathrm{D}_{4}-{ }^{7} \mathrm{~F}_{J=6,5}\right)$, which also provides another evidence for the energy transfer from $\mathrm{Ce}^{3+}$ to $\mathrm{Tb}^{3+}$. To know the energy transfer process, a series of samples with different concentrations of $\mathrm{Ce}^{3+}$ were prepared. Fig. $\mathrm{S} 5 \dagger$ shows the emission spectrum of the NSPO:0.01 $\mathrm{Tb}^{3+}, y \mathrm{Ce}^{3+}(y=0,0.05$, and 0.10$)$ phosphors upon an excitation wavelength of $278 \mathrm{~nm}$. When the $\mathrm{Tb}^{3+}$ doping concentration is fixed, the $\mathrm{Tb}^{3+}$ emission intensity increases monotonously and the $\mathrm{Ce}^{3+}$ emission intensity decreases as the $\mathrm{Ce}^{3+}$ ion concentration increases. This should be due to the enhancement of energy transfer from $\mathrm{Ce}^{3+}$ ions to $\mathrm{Tb}^{3+}$ ions.

The decay curves and lifetime of $\mathrm{Ce}^{3+}$ in NSPO:0.1 $\mathrm{Ce}^{3+}, y \mathrm{~Tb}^{3+}$ $(y=0,0.01)$ are showed in Fig. 9 According to the decay behavior of $\mathrm{Ce}^{3+}$, their corresponding luminescence decay curve can be best fitted to the typical second-order decay method by the following equation: ${ }^{57}$

$$
I_{(t)}=A_{1} \exp \left(-t / \tau_{1}\right)+A_{2} \exp \left(-t / \tau_{2}\right)
$$

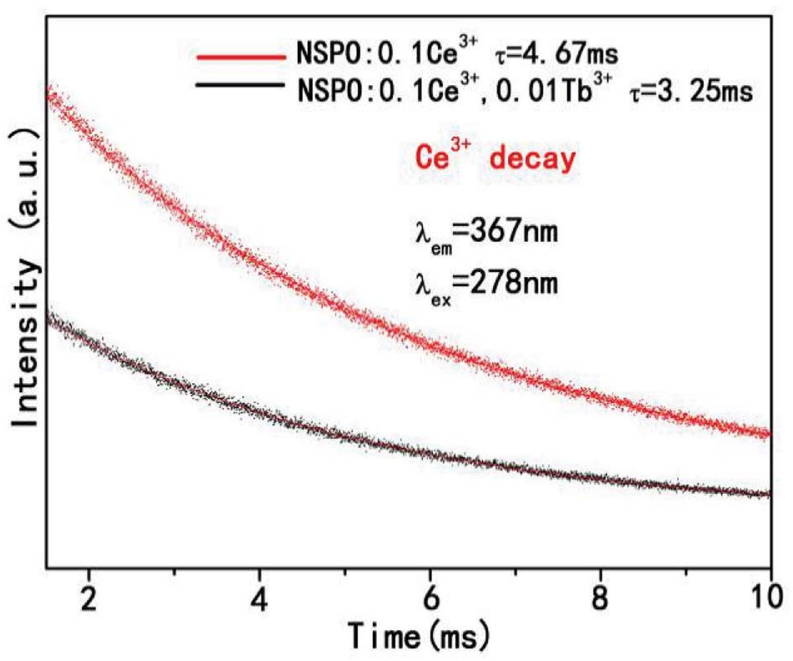

Fig. 9 The decay curves and lifetime of $\mathrm{Ce}^{3+}$ in NSPO:0.1Ce ${ }^{3+}, y \mathrm{~Tb}^{3+}$ $(y=0,0.01)$. 


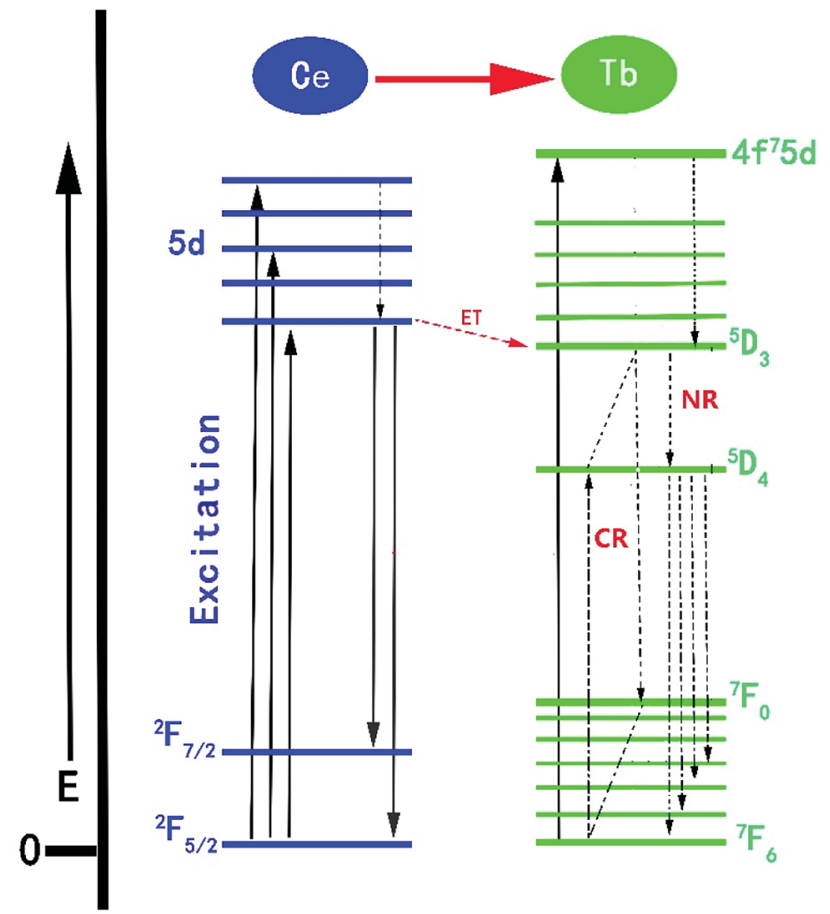

Fig. 10 Energy level model for the ET processes of $\mathrm{Ce}^{3+} \rightarrow \mathrm{Tb}^{3+}$ in NSPO host.

Here $I$ is the luminescence intensity at time $t ; A_{1}$ and $A_{2}$ are two constants which are related with the initial intensity; $\tau_{1}$ and $\tau_{2}$ are rapid and slow times for the exponential components, respectively. The average lifetime $(\tau)$ can be calculated using the following equation:

$$
\tau=\left(A_{1} \tau_{1}^{2}+A_{2} \tau_{2}^{2}\right)^{2} /\left(A_{1} \tau_{1}+A_{2} \tau_{2}\right)
$$

The lifetime of $\mathrm{Ce}^{3+}$ is $4.67 \mathrm{~ms}$ when doped only with $\mathrm{Ce}^{3+}$ ions in NSPO phosphors. However, the lifetime of $\mathrm{Ce}^{3+}$ decreases to $3.25 \mathrm{~ms}$ with the introduction of $\mathrm{Tb}^{3+}$, demonstrating the energy transfer from $\mathrm{Ce}^{3+}$ to $\mathrm{Tb}^{3+}$ by non-radiative processes. ${ }^{58}$

The proposed $\mathrm{Ce}^{3+} \rightarrow \mathrm{Tb}^{3+}$ ET process in the NSPO host is shown in Fig. 10. Firstly, $\mathrm{Ce}^{3+}$ ions can effectively absorb UV light from the ground state $\left({ }^{2} \mathrm{~F}_{5 / 2}\right)$ to the excited state ( $5 \mathrm{~d}$ energy levels) by UV irradiation. Secondly, these electrons relax to the lowest vibrational level of the excited state to release excess energy into the surrounding environment and then either return to the ground states to produce the $\mathrm{Ce}^{3+}$ emissions; or efficiently transfers the energy to the ${ }^{5} \mathrm{D}_{3}$ level of $\mathrm{Tb}^{3+}$, followed by non-radiative relaxation to ${ }^{5} \mathrm{D}_{4}$ level $\left({ }^{5} \mathrm{D}_{3}+{ }^{7} \mathrm{~F}_{6}={ }^{5} \mathrm{D}_{4}+{ }^{7} \mathrm{~F}_{0}\right)$ due to the same energy difference between ${ }^{5} \mathrm{D}_{3} \rightarrow{ }^{5} \mathrm{D}_{4}$ and ${ }^{7} \mathrm{~F}_{0}$ $\rightarrow{ }^{7} \mathrm{~F}_{6}$ in $\mathrm{Tb}^{3+}$ ions. ${ }^{56,59}$ Finally, as a result of the electrons moving from the ${ }^{5} \mathrm{D}_{4}$ excited state to the ${ }^{7} \mathrm{~F}_{J}(J=3,4,5,6)$ ground state, the green light is obtained.

\section{Conclusions}

In summary, we have successfully synthesized a series of color tunable NSPO: $\mathrm{Ce}^{3+} / \mathrm{Eu}^{3+} / \mathrm{Tb}^{3+}$ phosphors by a combination of hydrothermal method and low temperature calcinations (800 $\left.{ }^{\circ} \mathrm{C}\right)$. The obtained NSPO: $\mathrm{Ce}^{3+} / \mathrm{Eu}^{3+} / \mathrm{Tb}^{3+}$ phosphors were relatively uniform nanoparticles with size of $300 \mathrm{~nm}$. The energy transfer of $\mathrm{Tb}^{3+} / \mathrm{Eu}^{3+}$ co-doping as well as their tunable multicolor luminescence in $\mathrm{Na}_{3} \mathrm{Sc}_{2}\left(\mathrm{PO}_{4}\right)_{3}$ host lattices were realized. Due to energy transfer of $\mathrm{Tb}^{3+} \rightarrow \mathrm{Eu}^{3+}$, the emission colors of the resulting phosphor can be changed from green $(0.2865$, $0.4982)$ to red $(0.5693,0.2976)$ through yellow $(0.3657,0.4516)$ by adjusting the concentration of $\mathrm{Eu}^{3+}$. The obtained NSPO: $\mathrm{Ce}^{3+} / \mathrm{Eu}^{3+} / \mathrm{Tb}^{3+}$ phosphors can be promising as a potential candidate for the applications for solid-state lighting and display fields.

\section{Conflicts of interest}

There are no conflicts to declare.

\section{Acknowledgements}

This project is financially supported by the Fundamental Research Funds for the Central Universities (XDJK2016C147 and XDJK2018C050) and the National Natural Science Foundation of China (51302229).

\section{Notes and references}

1 P. Pust, V. Weiler, C. Hecht, A. Tucks, S. A. Wochnik, K. A. Henss, D. Wiechert, C. Scheu, J. P. Schmidt and W. Schnick, Nat. Mater., 2014, 13, 891-896.

2 A. A. Setlur, E. V. Radkov, C. S. Henderson, J. H. Her, A. M. Srivastava, N. Karkada, M. S. Kishore, N. P. Kumar, D. Aesram, A. Deshpande, B. L. Kolodin, S. Grigorov and U. Happek, Chem. Mater., 2010, 22, 4076-4082.

3 K. A. Denault, J. Brgoch, M. W. Gaultois, A. Mikhailovsky, R. Petry, H. Winkler, S. P. DenBaars and R. Seshadri, Chem. Mater., 2014, 26, 2275-2282.

4 Z. Ci, Q. Sun, S. Qin, M. Sun, X. Jiang, X. Zhang and Y. Wang, Phys. Chem. Chem. Phys., 2014, 16, 11597-11602.

5 X. Li, F. Liu, J. Y. Howe, J. Zhang, X. J. Wang, Z. Gu, C. Sun, R. S. Meltzer and Z. Pan, Light: Sci. Appl., 2013, 2, 3250-3257.

6 Y. Q. Li, A. C. A. Delsing, G. D. With and H. T. Hintzen, Chem. Mater., 2005, 17, 3242-3248.

7 K. Hanaoka, K. Kikuchi, T. Terai, T. Komatsu and T. Nagano, Chemistry, 2008, 14, 987-995.

8 C. H. Liang, F. B. Li, C. S. Liu, J. Lu and X. G. Wang, Dyes Pigm., 2008, 76, 477-488.

9 H. A. Höppe, Angew. Chem., Int. Ed., 2009, 48, 3572-3582.

10 E. F. Schubert and J. K. Kim, Science, 2005, 308, 1274-1278.

11 T. Justel, H. Nikol and C. Ronda, Angew. Chem., 1998, 37, 3084-3103.

12 W. Y. Tian, K. X. Song, F. F. Zhang, P. Zheng, J. X. Deng, J. Jiang, et al., J. Alloys Compd., 2015, 638, 249-253.

13 Z. G. Xia, H. Y. Du, J. Y. Sun, D. M. Chen and X. F. Wang, Mater. Chem. Phys., 2010, 119, 7-10.

14 J. K. Sheu, S. J. Chang, C. Kuo, Y. K. Su, L. Wu, Y. Lin, W. Lai, J. Tsai, G.-C. Chi and R. Wu, IEEE Photonics Technol. Lett., 2003, 15, 18-20. 
15 T. S. Chan, R. S. Liu and I. Baginskiy, Chem. Mater., 2008, 20, 1215-1217.

16 N. Guo, W. Lü, Y. Jia, W. Lv, Q. Zhao and H. You, ChemPhysChem, 2013, 14, 192-197.

17 D. Geng, M. Shang, Y. Zhang, H. Lian and J. Lin, Inorg. Chem., 2013, 52, 13708-13718.

$18 \mathrm{~W}$. Wu and Z. Xia, RSC Adv., 2013, 3, 6051-6057.

19 C. C. Lin, C. C. Shen and R. S. Liu, Chem.-Eur. J., 2013, 19, 15358-15365.

20 H. B. Liang, Y. Tao, J. H. Xu, H. He, H. Wu and W. X. Chen, J. Solid State Chem., 2004, 117, 901-908.

21 Z. J. Wang, S. Q. Lou and P. L. Li, J. Alloys Compd., 2014, 586, 536-541.

22 V. V. Tkachev, V. I. Ponomarev and L. O. Atovmyan, Zhurnal Strukturnoj Khimii, 1984, 25, 128-134.

23 B. I. Lazoryak, V. B. Kalinin, S. Y. Stefanovich and V. A. Efremov, Dokl. Akad. Nauk SSSR, 1980, 250, 861-864.

24 N. Guo, Y. H. Zheng, Y. C. Jia, H. Qiao and H. P. You, J. Phys. Chem. C, 2012, 116, 1329-1334.

25 K. Hirohumi, Master thesis, Niigata University, 2013.

26 H. Guo, X. Y. Huang and Y. J. Zeng, J. Alloys Compd., 2018, 741, 300-306.

27 H. Guo, B. Devakumar, B. Li and X. Y. Huang, Dyes Pigm., 2018, 151, 81-88.

28 R. Vijayakumar, H. Guo and X. Y. Huang, Dyes Pigm., 2018, 156, 8-16.

29 X. C. Wang, Z. Y. Zhao, Q. S. Wu, C. Wang, Q. Wang, Y. Y. Li and Y. H. Wamg, J. Mater. Chem. C, 2016, 4, 8795-8801.

30 Y. S. Liu, D. T. Tu, H. M. Zhu and X. Y. Chen, Chem. Soc. Rev., 2013, 42, 6924-6958.

31 X. Teng, Y. H. Zhu, W. Wei, S. C. Wang, J. F. Huang, R. Naccache, W. B. Hu, A. L. Y. Tok, Y. Han, Q. C. Zhang, Q. Y. Fan, W. Huang, J. A. J. Capobianco and L. Huang, J. Am. Chem. Soc., 2012, 134, 8340-8343.

32 Y. J. Ding, X. Teng, H. Zhu, L. L. Wang, W. B. Pei, J. J. Zhu, L. Huang and W. Huang, Nanoscale, 2013, 5, 11928-11932.

33 H. Y. Jiao and Y. H. Wang, J. Electrochem. Soc., 2009, 156, 117-120.

34 H. Yamamoto and K. Urade, J. Electrochem. Soc., 1982, 129, 2069-2074.

35 D. Wang, Y. Wang and J. W. He, Mater. Res. Bull., 2012, 47, 142-145.

36 D. Q. Geng, G. G. Li, M. M. Shang, C. Peng, Y. Zhang, Z. Y. Cheng and J. Lin, Dalton Trans., 2012, 41, 3078-3086.

37 K. Pavani, J. Suresh Kumar and L. Rama Moorthy, J. Alloys Compd., 2014, 586, 722-729.
38 M. Back, M. Boffelli, A. Massari, R. Marin, F. Enrichi and P. Riello, J. Nanopart. Res., 2013, 15, 1753-1758.

39 N. Guo, Y. H. Song, H. P. You, G. Jia, M. Yang, K. Liu, et al., Eur. J. Inorg. Chem., 2010, 29, 4636-4642.

40 W. P. Chen, H. B. Liang, B. Han, J. P. Zhong and Q. Su, J. Phys. Chem. C, 2009, 113, 17194-17199.

41 J. Ding, Q. Zhang, J. Cheng and X. Liu, J. Alloys Compd., 2010, 495, 205-208.

42 Z. G. Xia and R. S. Liu, J. Phys. Chem. C, 2012, 116, 1560415609.

43 L. E. Muresan, Y. Karabulut, A. I. Cadis, I. Perhaita, A. Canimoglu and J. Garcia Guinea, J. Alloys Compd., 2016, 658, 356-366.

44 Q. H. Zhang, H. Y. Ni, L. L. Wang and F. M. Xiao, Ceram. Int., 2016, 42, 6115-6120.

45 Z. F. Yang, Y. H. Hu, L. Chen, X. J. Wang and G. F. Ju, Mater. Sci. Eng,. B: Solid State. Mater. Adv. Technol., 2015, 193, 2731.

46 L. Macalik, P. E. Tomaszewski, R. Lisiecki and J. Hanuza, J. Solid State Chem., 2008, 181, 2591-2600.

47 Z. X. Tao, T. Tsuboi, Y. L. Huang, W. Huang, P. Q. Cai and H. J. Seo, Inorg. Chem., 2014, 53, 4161-4168.

48 S. Y. Xin, Y. H. Wang, G. Zhu, X. Ding, W. Y. Geng and Q. Wang, Dalton Trans., 2015, 44, 16099-16106.

49 P. I. Paulose, G. Jose, V. Thomas, N. V. Unnikrishnan and M. K. R. Warrier, J. Phys. Chem. Solids, 2003, 64, 841-846.

50 R. Reisfeld, E. Greenberg, R. Velapoldi and B. Barnett, J. Chem. Phys., 1972, 56, 1698-1705.

51 B. M. Antipeuko, I. M. Bataev, V. L. Ermolaev, E. I. Lyubimov and T. A. Privalova, Opt. Spectrosc., 1970, 29, 177-184.

52 G. Blasse, J. Solid State Chem., 1986, 62, 207-211.

53 H. Jiao, F. Liao, S. Tian and X. J. Jing, J. Electrochem. Soc., 2003, 150, 220.

54 D. L. Dexter and J. A. Schulman, J. Chem. Phys., 1954, 22, 1063-1070.

55 Z. G. Xia, J. Q. Zhuang, A. Meijerink and X. P. Jing, Dalton Trans., 2013, 42, 6327-6336.

56 J. Hao, S. A. Studenikin and M. Cocivera, J. Appl. Phys., 2001, 90, 5064-5069.

57 H. L. Li, Z. L. Wang, S. J. Xu and J. H. Hao, J. Electrochem. Soc., 2009, 156, 112-116.

58 J. Y. Sun, X. Y. Zhang, Z. G. Xia and H. Y. Du, Mater. Res. Bull., 2011, 46, 2179-2182.

59 D. W. Wen and X. J. Shi, Dalton Trans., 2013, 42, 1662116629. 